\title{
Kinetico-Mechanistic Information about Alkene Hydroamination with Aniline in Bromide-rich Ionic Media: Importance of Solvolysis
}

\author{
Gabriel Aullón, ${ }^{a}$ Kerman Gómez, ${ }^{b}$ Gabriel González, ${ }^{b}$ Susanna Jansat, ${ }^{a}$ Manuel Martínez, ${ }^{a}$ \\ Rinaldo Poli, ${ }^{c, d}$ and Mireia Rodríguez-Zubiri. ${ }^{c}$ \\ ${ }^{a}$ Departament de Química Inorgànica, Universitat de Barcelona, Martí i Franquès 1-11, E- \\ 08028 Barcelona, SPAIN. \\ b Institut Català d'Investigació Química, Avinguda dels Països Catalans 16, E-43007 \\ Tarragona, SPAIN \\ ${ }^{\mathrm{c}}$ CNRS, LCC (Laboratoire de Chimie de Coordination), 205 Route de Narbonne, Université de \\ Toulouse, UPS, INP, F-31077 Toulouse, FRANCE \\ ${ }^{\mathrm{d}}$ Institut Universitaire de France, 103 Boulevard Saint Michel, 75005 Paris, FRANCE
}

\begin{abstract}
The study of the $\left[\mathrm{PtBr}_{4}\right]^{2-}$ reactivity with hexene and aniline in highly ionic $\left(\mathrm{Bu}_{4} \mathrm{P}\right) \mathrm{Br} / \mathrm{CH}_{2} \mathrm{Br}_{2}$ media has been studied from a kinetico-mechanistic perspective. The results indicate bromide ion association to the square-planar starting material to produce a stable diamagnetic compound that can be described as an ion-pair of a $\left[\mathrm{PtBr}_{5}\right]^{3-}$ square pyramidal complex stabilized by several phosphonium counter-cations. While this species reacts rapidly with aniline, producing the known square-planar complex $\left[\mathrm{PtBr}_{3}\left(\mathrm{PhNH}_{2}\right)\right]^{-}$with release of the apical bromide of the square pyramidal intermediate, the reaction with hexene producing the square-planar $\left[\mathrm{PtBr}_{3}(\text { hexene })\right]^{-}$complex is much slower. The thermal and pressure activation parameters determined for these processes fully agree with the proposed reactivity. The gross features of the platinum-catalyzed hydroamination mechanism, occurring via much higherenergy transition states, are not necessarily altered by these new findings, given the fact that all ligand exchange reactions occur with relative low activation barriers. Nevertheless, the nature of the catalyst resting state needs revision as demonstrated. The importance of explicitly considering the solvent for reactions conducted in non-innocent highly organized media, is also highlighted.
\end{abstract}




\section{INTRODUCTION}

Hydroamination, one of the available processes to form $\mathrm{C}-\mathrm{N}$ bonds, consists in the direct addition of an N-H bond across an unsaturated C-C bond and represents an atom economical approach for the synthesis of amines from ammonia or lower amines. Since amines are a very important class of chemicals in today's World market, the hydroamination reaction generates a lot of interest for academic and industrial researchers. ${ }^{1,2}$ The reaction is particularly challenging for alkenes, less reactive than other unsaturated substrates, such as alkynes, dienes and allenes, particularly when they are not activated, and for the intermolecular version. Catalytic approaches have been considered for the latter on non-activated olefins and a moderate success has been achieved using pre-catalysts based on lanthanides, ${ }^{3,4} \mathrm{Zr},{ }^{5} \mathrm{Fe},{ }^{6} \mathrm{Ru},{ }^{7,8}$ $\mathrm{Rh},{ }^{9,10} \mathrm{Ir},{ }^{10} \mathrm{Pd},{ }^{11,12} \mathrm{Pt},{ }^{13-19} \mathrm{Ag}^{20}$ and Au. ${ }^{21-23}$ Among other metals, for Pt-catalyzed systems two basic types of catalyst dependent mechanisms have been indicated, one where the metal centre first activates the olefin, followed by nucleophilic attack by the amine, the second one involving amine activation and subsequent olefin insertion into the metal-N bond. ${ }^{24,25}$ Recent work carried out in one of our groups has addressed the mechanism for the system introduced by Brunet, which is legitimately the simplest platinum-based catalyst since it is composed by ordinary commercially available $\mathrm{PtBr}_{2}$ activated in the presence of an excess of $\left(\mathrm{Bu}_{4} \mathrm{P}\right) \mathrm{Br}$ and functions in the absence of additional expensive ligands. It is also one of the most practical catalytic systems because it is stable and can operate in the presence of air and water, and provides the highest activities among all Pt-based catalysts reported to date. Thus, the improvement of the catalytic efficiency will only be attained by a comprehensive knowledge of the mechanism and the effect of the non innocent media used $(0.13 \mathrm{M}$ $\left.\left(\mathrm{Bu}_{4} \mathrm{P}\right) \mathrm{Br}\right)$. In particular, synthetic work using ethylene as representative olefin and lowtemperature equilibrium studies, backed up by theoretical calculations, have assessed the relative stability in solution (mostly using dichloromethane, but also aniline and DMF) of a variety of simple $\mathrm{Pt}^{\mathrm{II}}$ complexes containing all ligands that are present under catalytic conditions (ethylene, aniline, bromide ions). ${ }^{24,26-28}$ Subsequent computational investigations on the high-energy portion of the catalytic cycle, which is experimentally inaccessible to stoichiometric studies, have confirmed the olefin-activation mechanism as the operating cycle for the Pt-catalyzed process and unveiled intimate details of each elementary step of the catalytic cycle. ${ }^{28,29}$ Nevertheless, in these studies the involvement of the highly ionic media, 
found definitively relevant empirically, has not been fully addressed given the obvious limitations in the calculation procedures.

Kinetico-mechanistic studies on hydroamination processes have been carried out in the presence of $\left[\mathrm{PtL}_{2}(\mathrm{OTf})_{2}\right]$ as catalyst $\left(\mathrm{L}_{2}=\text { bipy, diimine, diphosphine }\right)^{19}$ and the preparation of several possible low-energy intermediates in the proposed catalytic cycle has been attained for the ligand-free $\mathrm{PtBr}_{2} /\left(\mathrm{Bu}_{4} \mathrm{P}\right) \mathrm{Br}$ catalyst. ${ }^{30}$ For the latter catalytic system, despite the obvious stoichiometric implications of the non-innocent medium $\left(0.13 \mathrm{M}\left(\mathrm{Bu}_{4} \mathrm{P}\right) \mathrm{Br}\right)$ that has been established as ideal from a catalyses perspective, ${ }^{13}$ its importance in the kinetics and mechanism of the cycle has not been explored. Given our interest in the effect of the medium on the kinetics and mechanisms of many well established reaction processes, ${ }^{31-38}$ and our experience in kinetico-mechanistic studies on organometallic complexes, ${ }^{33,38-42}$ we have decided to explore the importance of such a high ionic medium in the $\mathrm{PtBr}_{2} /\left(\mathrm{Bu}_{4} \mathrm{P}\right) \mathrm{Br}$ catalyzed hydroamination process through a kinetico-mechanistic study.

In this contribution we present the unexpected solution chemistry of the $\left[\mathrm{PtBr}_{4}\right]^{2-}$ species in highly ionic $\left(\mathrm{Bu}_{4} \mathrm{P}\right) \mathrm{Br}$ media (from 0.016 to $2 \mathrm{M}$ in $\left.\mathrm{CH}_{2} \mathrm{Br}_{2}\right)$ and its further reaction with aniline and/or hexene. The results indicate the association of bromide ions to the square-planar starting material to produce a stable diamagnetic compound that can be described as an ionpair of a $\left[\mathrm{PtBr}_{5}\right]^{3-}$ square pyramidal complex. This species, which is associated with the nature of the starting $\mathrm{Pt}^{\mathrm{II}}$ centre under catalytic conditions $\left(0.13-1.0 \mathrm{M}\left(\mathrm{Bu}_{4} \mathrm{P}\right) \mathrm{Br}\right.$ in aniline), reacts readily with aniline in a series of consecutive equilibria on very different time scales via the stepwise substitution of the bromido ligands by $\mathrm{PhNH}_{2}$, as seen by the inverse reaction rate dependence on $\left(\mathrm{Bu}_{4} \mathrm{P}\right) \mathrm{Br}$ concentration. Addition of hexene, at very high concentrations, to preformed $\left[\mathrm{PtBr}_{5}\right]^{3-}$ solutions in $\mathrm{CH}_{2} \mathrm{Br}_{2}$ do not produce any measurable reaction under time and temperature conditions equivalent to those used in the reaction with aniline. This fact, in clear contrast with that observed for simple $\left[\mathrm{PtBr}_{4}\right]^{2-}$ plus hexene systems, suggest that the sequence indicated in the proposed catalytic cycle for the hydroamination of ethylene needs revision when hexene is considered as the substrate in a bromide-rich environment. The only reactivity with hexene was observed on equilibrated, aniline free, $\left[\mathrm{PtBr}_{4}\right]^{2-} / \mathrm{Br}^{-}$mixtures at temperatures much higher than those utilized for its reaction with aniline. The results suggest that the catalytic cycle should include the $\left[\mathrm{PtBr}_{5}\right]^{3-}$ resting state that undergoes a bromide by aniline substitution to generate either an off-loop species from the catalytic cycle or a slow subsequent reaction with hexene, thus slightly modifying the sequence generally accepted. 


\section{RESULTS AND DISCUSSION}

Reactivity of $\left[\mathrm{PtBr}_{4}\right]^{2-}$ in $\left(\mathrm{Bu}_{4} \boldsymbol{P}\right)$ Br-rich media Given the fact that the $\mathrm{PtBr}_{2}$-catalyzed hydroamination of alkenes occurs with much better results in the presence of $\left(\mathrm{Bu}{ }_{4} \mathrm{P}\right) \mathrm{Br}$, a preliminary study about the solution chemistry and stability of the presumed $\left(\mathrm{Bu}_{4} \mathrm{P}\right)_{2}\left[\mathrm{PtBr}_{4}\right]$ precatalyst in $\mathrm{CH}_{2} \mathrm{Br}_{2} /\left(\mathrm{Bu}_{4} \mathrm{P}\right) \mathrm{Br}$ medium was pursued. The choice of $\mathrm{CH}_{2} \mathrm{Br}_{2}$ as accompanying solvent rather than $\mathrm{CH}_{2} \mathrm{Cl}_{2}$ was based on its high boiling point $\left(97^{\circ} \mathrm{C}\right)$, which allows the work at high temperature under conditions rather similar to those encountered in the catalytic processes and in the absence of undesirable halide exchange processes. The high solubility of $\left(\mathrm{Bu}_{4} \mathrm{P}\right) \mathrm{Br}$ in this solvent $(c a .3 \mathrm{M})$ is also convenient for the purposes of this study.

Preliminary studies on $\mathrm{CH}_{2} \mathrm{Br}_{2}$ solutions of $\left(\mathrm{Bu}_{4} \mathrm{P}\right)_{2}\left[\mathrm{PtBr}_{4}\right]$, prepared as indicated in the literature ${ }^{43}$ showed important colour changes with time that are associated with the loss of bromido ligands and subsequent polymerization, as described in the literature. ${ }^{43-45}$ These processes should be easily suppressed by the addition of an excess of $\left(\mathrm{Bu}_{4} \mathrm{P}\right) \mathrm{Br}$. In this respect, ${ }^{195} \mathrm{Pt}$ NMR experiments were conducted on chloroform solutions of $\left(\mathrm{Bu}_{4} \mathrm{P}\right)_{2}\left[\mathrm{PtBr}_{4}\right]$ containing an excess of $\left(\mathrm{Bu}_{4} \mathrm{P}\right) \mathrm{Br}$ in order to establish which reactivity was taking place under these conditions. Figure 1 collects the time evolution of a ${ }^{195} \mathrm{Pt}$ NMR spectrum of a $1 \mathrm{M}\left(\mathrm{Bu}_{4} \mathrm{P}\right) \mathrm{Br}$ $\mathrm{CDCl}_{3}$ solution of $\left(\mathrm{Bu}_{4} \mathrm{P}\right)_{2}\left[\mathrm{PtBr}_{4}\right](0.10 \mathrm{M})$ at room temperature. It is evident that at time zero only the broad signal corresponding to $\left[\mathrm{PtBr}_{4}\right]^{2-}$ at $-2500 \mathrm{ppm}$ is relevant, while its intensity decreases with time in favour of a final sharp single signal at $-2000 \mathrm{ppm}$, not related to any known $\mathrm{Pt}^{\mathrm{II} / \mathrm{Br}}$ or $\mathrm{Pt}^{\mathrm{IV}} / \mathrm{Br}$ complexes. ${ }^{43,44}$ Monitoring by ${ }^{1} \mathrm{H}$ or ${ }^{31} \mathrm{P} \mathrm{NMR}$ spectroscopy of similar experiments indicated that no reaction involving the $\mathrm{Bu}_{4} \mathrm{P}^{+}$cation occurs. Furthermore, the observed important UV-Vis spectral changes in $\mathrm{CH}_{2} \mathrm{Br}_{2}$ (see below) are also evident both in $\mathrm{CHCl}_{3}$ and when $\left(\mathrm{NEt}_{4}\right) \mathrm{Br}$ solutions of the same concentrations are used, indicating that the bromide ion is responsible for the observed changes. When the experiments were conducted using acetonitrile instead of dibromomethane no significant changes were observed by UV-Vis spectroscopy. It seems clear that a low polarity solvent is needed for the reaction with high bromide concentrations to occur; alternatively the reason could also be associated to the coordinating characteristics of $\mathrm{CH}_{3} \mathrm{CN}$, which should allow its competition with $\mathrm{Br}^{-}$. A similar behaviour both in UV-Vis spectra and ${ }^{195} \mathrm{Pt} \operatorname{NMR}(\Delta \delta \approx 1000 \mathrm{ppm}$ downfield) has been observed in the formation of crystallographically characterized pentacoordinated adducts of organometallic pincer complexes with $\mathrm{SO}_{2}{ }^{46,47}$ 
a)

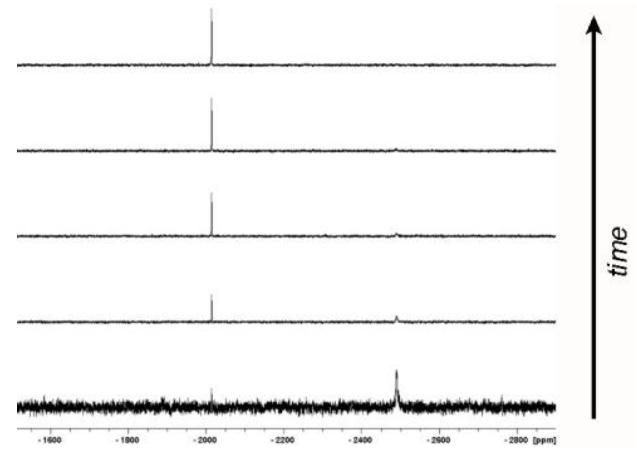

b)

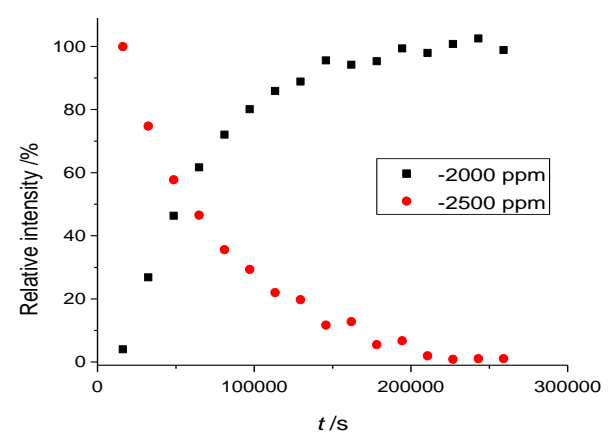

Figure 1.- $\boldsymbol{a})$ Time resolved ${ }^{195} \mathrm{Pt}$ NMR spectra of a $0.1 \mathrm{M}\left(\mathrm{Bu}_{4} \mathrm{P}\right)_{2}\left[\mathrm{PtBr}_{4}\right]$ and $1.0 \mathrm{M}\left(\mathrm{Bu}_{4} \mathrm{P}\right) \mathrm{Br}$ solution in $\mathrm{CDCl}_{3}$ at room temperature; time between spectra 9 h. $\boldsymbol{b}$ ) Time evolution of the signal integrals

UV-Vis monitoring of the reaction progress, using pseudo-first order conditions, produced very well behaved time resolved spectra (Figure 2a) that could be perfectly fitted to by a single exponential from which $k_{\mathrm{obs}}$ values could be derived. These were found independent on the platinum concentration but showed a limiting dependence with $\left[\left(\mathrm{Bu}_{4} \mathrm{P}\right) \mathrm{Br}\right]$ and with a non-zero intercept. The fact that the spectral changes increase with increasing the value of $\left[\left(\mathrm{Bu}_{4} \mathrm{P}\right) \mathrm{Br}\right]$ suggests the establishment of an equilibrium $\left(k_{+} / k_{-}=K_{\text {eq }}\right)$ with a preformed outer-sphere species $\left(K_{\mathrm{OS}}\right)$, i.e. $k_{\mathrm{obs}}=k_{-}+\left\{k_{+} K_{\mathrm{OS}}\left[\left(\mathrm{Bu}_{4} \mathrm{P}\right) \mathrm{Br}\right] /\left(1+K_{\mathrm{OS}}\left[\left(\mathrm{Bu}_{4} \mathrm{P}\right) \mathrm{Br}\right]\right)\right\}^{48,49}$. Figure $2 \mathrm{~b}$ collects the observed trend at different temperatures. Derivation of $k_{+}, k_{-}$and $K_{\mathrm{OS}}$ at different temperatures produced the thermal activation parameters collected in Table 1 by the use of Eyring plots. The dependence of $\ln k_{\text {obs }}$ with pressure at $1.0 \mathrm{M}\left(\mathrm{Bu}_{4} \mathrm{P}\right) \mathrm{Br}$ (where $\left.k_{\mathrm{obs}} \approx k_{+}\right)$was taken as a measure of the activation volume for the forward process and the value is also collected in Table 1.

a)

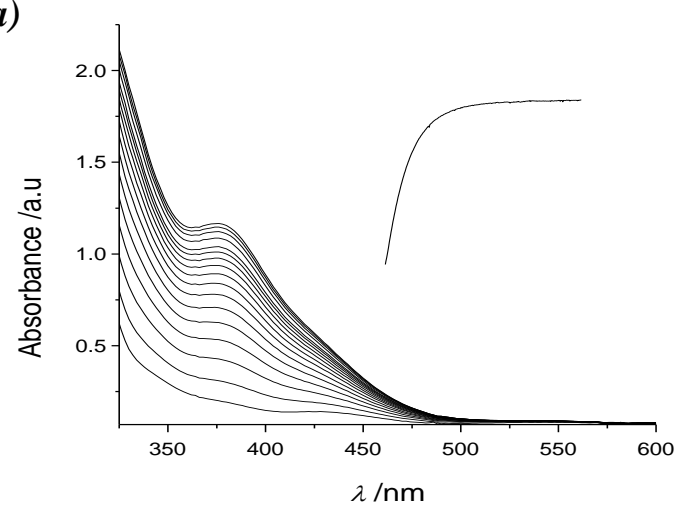

b)

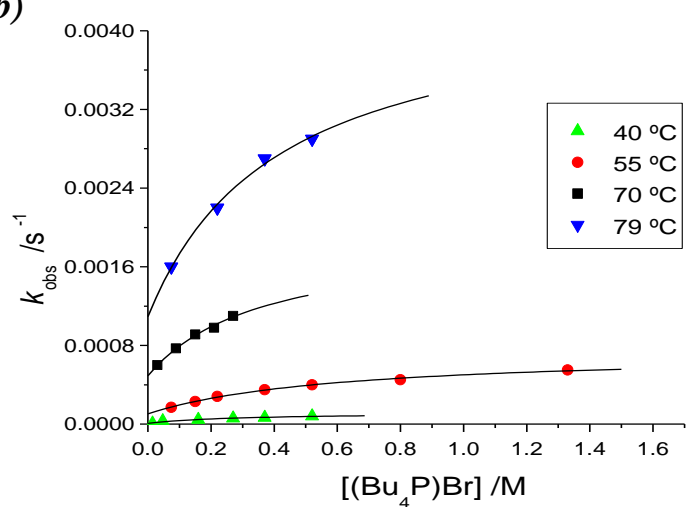

Figure 2.- $\boldsymbol{a})$ Time resolved UV-Vis spectra of a of $\left(\mathrm{Bu}_{4} \mathrm{P}\right)_{2}\left[\mathrm{PtBr}_{4}\right]\left(4.5 \times 10^{-4} \mathrm{M}\right)$ and $\left(\mathrm{Bu}_{4} \mathrm{P}\right) \mathrm{Br}(0.27 \mathrm{M})$ $\mathrm{CH}_{2} \mathrm{Br}_{2}$ solution at $70^{\circ} \mathrm{C}$ (inset corresponds to the absorbance changes at $375 \mathrm{~nm}$, total time $2 \mathrm{~h}$ ). b) Plot at different temperatures of the dependence of $k_{\mathrm{obs}}$ on $\left[\left(\mathrm{Bu}{ }_{4} \mathrm{P}\right) \mathrm{Br}\right]$ for the reaction observed. 
Table 1.- Kinetic, equilibrium and thermal and pressure activation parameters for the reaction observed between $\left(\mathrm{Bu}_{4} \mathrm{P}\right)_{2}\left[\mathrm{PtBr}_{4}\right]$ and $\left(\mathrm{Bu}_{4} \mathrm{P}\right) \mathrm{Br}$ in $\mathrm{CH}_{2} \mathrm{Br}_{2}$ solution.

\begin{tabular}{c|c|c|c|c}
${ }^{328} k_{+} / \mathrm{s}^{-1}$ & $\Delta H_{+} \neq / \mathrm{kJ} \mathrm{mol}^{-1}$ & $\Delta S_{+}{ }^{\ddagger} / \mathrm{J} \mathrm{K}^{-1} \mathrm{~mol}^{-1}$ & ${ }^{328} \Delta V_{+}^{\ddagger} / \mathrm{cm}^{3} \mathrm{~mol}^{-1}$ & ${ }^{328} K_{\mathrm{OS}} / \mathrm{M}^{-1}$ \\
\hline $6.4 \times 10^{-4}$ & $76 \pm 7$ & $-22 \pm 22$ & $-20 \pm 1$ & 3.0 \\
\hline \hline${ }^{328} k_{-} / \mathrm{s}^{-1}$ & $\Delta H_{-}^{\ddagger} / \mathrm{kJ} \mathrm{mol}^{-1}$ & $\Delta S_{-}^{\ddagger} / \mathrm{J} \mathrm{K} \mathrm{mol}^{-1}$ & \\
\hline $1.0 \times 10^{-4}$ & $117 \pm 10$ & $30 \pm 30$ &
\end{tabular}

All the above indications are consistent with the reaction being the addition of a bromide ligand to the system, as depicted in Equation 1. The negative activation entropy and particularly the negative activation volume are strong indicators of the associative character of the forward process. The relatively small value determined for $\Delta S_{+}{ }^{\ddagger}$ agrees with the already important ordering of the ionic atmosphere prior to bromide ion addition. Similarly, the reverse reaction shows a set of values for $\Delta H^{\ddagger_{-}}$and $\Delta S^{\ddagger_{-}}$that are in line with a dissociatively activated process. As for the values of the equilibrium constant, defined as $k_{+} / k_{-}$, they show a small increase at low temperatures (from $3\left(79^{\circ} \mathrm{C}\right)$ to $\left.15\left(40^{\circ} \mathrm{C}\right)\right)$, which indicates a higher presence of the $\left[\mathrm{PtBr}_{5}\right]^{3-}$ at the lower temperatures in the study.

$$
\left[\mathrm{PtBr}_{4}\right]^{2-}+\mathrm{Br}^{-} \stackrel{K_{\mathrm{OS}}}{\rightleftarrows}\left\{\left[\mathrm{PtBr}_{4}\right]^{2-} ; \mathrm{Br}^{-}\right\} \stackrel{k_{+}}{\rightleftarrows}\left[\mathrm{PtBr}_{5}\right]^{3-}
$$

The presence of a definite value of $K_{\text {eq }}$ is surprising given the full disappearance of the ${ }^{195} \mathrm{Pt}$ NMR signal of the starting $\left[\mathrm{PtBr}_{4}\right]^{2-}$ material (Figure 1) in $\mathrm{CDCl}_{3}$. This seems to point to the need of a very low polarity medium to stabilize the new species, which again is in line with the lack of reactivity observed in $\mathrm{CH}_{3} \mathrm{CN}$ indicated above (empirical solvent polarity scale being 0.26 for $\mathrm{CHCl}_{3}, 0.27$ for $\mathrm{CH}_{2} \mathrm{Br}_{2}$ and 0.46 for $\left.\mathrm{CH}_{3} \mathrm{CN}\right) .{ }^{50}$ Finally considering that the outersphere complex $\left\{\left[\mathrm{PtBr}_{4}\right]^{2-} ; \mathrm{Br}^{-}\right\}$occurs between two negatively charged species, the rather high value determined for the outer-sphere complex formation equilibrium constant, $K_{\mathrm{OS}}$, is a clear indication of the complicated nature of the "strictly" non-bonding interactions.

This type of pentacoordinate species has already been fully established in solution, apart from the $\mathrm{SO}_{2}$ adduct of the above mentioned $\mathrm{Pt}^{\mathrm{II}}$-pincer complex, ${ }^{46,47}$ by EXAFS measurements and theoretical calculations on aqueous acidic solutions of $\left[\mathrm{Pt}\left(\mathrm{OH}_{2}\right)_{4}\right]^{2+}{ }^{51,52}$ The existence of $\left[\mathrm{Pd}\left(\mathrm{OH}_{2}\right)_{5}\right]^{2+}$ and hydrated forms of $\left[\mathrm{PtCl}_{4}\right]^{2-}$ and $\left[\mathrm{PdCl}_{4}\right]^{2-}$ (showing a geometry that can be better described as an octahedral diamagnetic complex with a very strong Jahn-Teller effect), 
have also been indicated. ${ }^{53,54}$ Even the formation of square pyramidal $\left[\mathrm{Ni}(\mathrm{CN})_{5}\right]^{3-}$ in solution has been reported, as well as other $\mathrm{Ni}^{\mathrm{II}}$ five coordinated complexes. ${ }^{55,56} \mathrm{An}$ analysis of the Cambridge database indicates a definite preferential formation of square pyramidal pentacoordinated $\mathrm{Pt}^{\mathrm{II}}$ complexes for non-tripoidal ligands. Given the filled $d_{\mathrm{z} 2}$ orbital on the $\mathrm{Pt}^{\mathrm{II}}$ centre, their apical bond lengths are definitively longer than their basal counterparts, from all these available data, the apical Pt-Br bond length can be reasonably estimated around the 2.90 $\AA$ 注 of the activation entropy for the association process. In this respect, the reverse reaction should be dissociatively activated as expected for the microreversibility principle. Effectively, as indicated before the value for $\Delta S_{-} \neq$is more positive although small, as corresponding to the dissociation of an already elongated Pt-Br bond. ${ }^{57}$ These facts are a good example of the need of considering the effects of non-innocent Lewis base media in reactions occurring at low solute concentrations (i.e. very large solvent:solute ratios) that allow the existence of otherwise undefined solvento species. ${ }^{33,58}$

Given the non-feasibility of the isolation, workup and further characterization of the species formed in the above mentioned reaction conditions, DFT calculations were tried for the putative $\left[\mathrm{PtBr}_{5}\right]^{3-}$ anion and their ion-paired species. Although in other systems these have led to reliable results, ${ }^{59}$ for our system no optimization of the desired species could be been achieved. ${ }^{60}$

Reactivity of $\left[\mathrm{PtBr}_{4}\right]^{2-}$ with aniline in $\left(\mathrm{Bu}_{4} \mathrm{P}\right) \mathrm{Br}$ media Given the reactivity observed for $\left[\mathrm{PtBr}_{4}\right]^{2-}$ in concentrated $\mathrm{CH}_{2} \mathrm{Br}_{2}$ solutions of $\left(\mathrm{Bu}_{4} \mathrm{P}\right) \mathrm{Br}$, the reactivity of these equilibrated reaction mixtures with $\mathrm{PhNH}_{2}$ was further pursued. This is especially interesting after our recently appeared ${ }^{30}$ report about all the species present on equilibration of $\left[\mathrm{PtBr}_{4}\right]^{2-} / \mathrm{PhNH}_{2} / \mathrm{C}_{2} \mathrm{H}_{4}$ systems in $\mathrm{CH}_{2} \mathrm{Cl}_{2}$ solution at room temperature. From the data it is clear that a rather complex series of equilibria exists, even in the absence of important relative concentrations of $\left(\mathrm{Bu}_{4} \mathrm{P}\right) \mathrm{Br}$. Nevertheless, in the reported cases the nature of the starting material was neatly set to $\left(\mathrm{Bu}_{4} \mathrm{P}\right)_{2}\left[\mathrm{PtBr}_{4}\right]$, which is not the case in the present report that deals with a set of reaction conditions much closer to those needed for the improved catalytic cycles. ${ }^{14,24}$ Solutions of $\left(\mathrm{Bu}_{4} \mathrm{P}\right)_{2}\left[\mathrm{PtBr}_{4}\right]\left(c a .4 \times 10^{-4} \mathrm{M}\right)$ and $\left(\mathrm{Bu}_{4} \mathrm{P}\right) \mathrm{Br}(1.0 \mathrm{M})$ in $\mathrm{CH}_{2} \mathrm{Br}_{2}$ were heated at $50^{\circ} \mathrm{C}$ until equilibration $\left(2-3 \mathrm{~h}, k_{+} / k_{-}=7\right.$, see above). Aliquots of these solutions were mixed with different aniline solutions of different concentrations and at the same ionic 
strength in $\mathrm{CH}_{2} \mathrm{Br}_{2}$; the final platinum concentration was usually in the $(1.0-2.5) \times 10^{-4} \mathrm{M}$ range. As expected, time resolved UV-Vis monitoring of the reaction showed a series of processes, the relative importance of which was highly dependent on the temperature, time and aniline concentration. Nevertheless, very long reaction times or high temperatures were avoided in order to overcome the problems caused by side reactions of the aniline. In all cases a blank experiment in the absence of added platinum was conducted to establish the reliability limit of the experiments.

The first monitored process is very fast and can be observed within the stopped-flow equipment limits, despite the high viscosity and density of the solutions used. The process is very clean and a good retention of isosbestic points is observed (Figure 3a). Furthermore, this step is an equilibrium reaction, as detected by the important intercepts of the plots of the pseudo-first order observed rate constants $\left(k_{\mathrm{obs} 1}\right)$ versus [aniline] (Figure $3 \mathrm{~b}$ ); Figure $3 \mathrm{c}$ also collects the trend observed for the $\ln k_{1 \text { off }}$ versus $P$ plots for the intercepts measured as a function of pressure. Table 2 collects the series of relevant kinetic and thermal and pressure activation parameters for the reaction. Following this very fast reaction a second process on a very different time-scale is also observed with similar UV-Vis spectral changes yielding a set of values for $k_{\mathrm{obs} 2}$, also varying linearly with the concentration of aniline (Table S1, Supporting information) and showing a definite intercept. Before the side reactions of aniline take place, with a dramatic exponential increase of the absorbance of the spectrum, a third process is neatly observed during the monitoring of UV-Vis spectral changes. The spectral changes and [aniline]-dependence of this $k_{\text {obs } 3}$ values are equivalent to those observed for the first two processes and the relevant parameters are also collected in Table 2 together with those for $k_{\mathrm{obs} 2}$.

a)

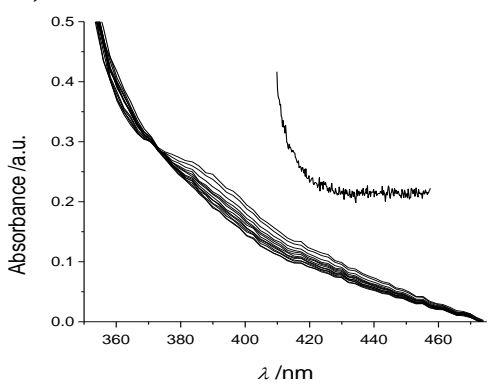

b)

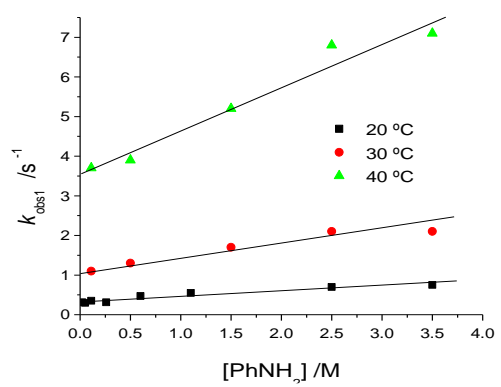

c)



Figure 3.- a) Time resolved UV-Vis spectra of the evolution of a $\mathrm{CH}_{2} \mathrm{Br}_{2}$ solution of putative $\left[\mathrm{PtBr}_{5}\right]^{3-}$ $\left(2 \times 10^{-4} \mathrm{M}\right),\left(\mathrm{Bu}_{4} \mathrm{P}\right) \mathrm{Br}(1.0 \mathrm{M})$ and $\mathrm{C}_{6} \mathrm{H}_{5} \mathrm{NH}_{2}(0.6 \mathrm{M})$ at $20^{\circ} \mathrm{C}$ and $1 \mathrm{~atm}$ (inset corresponds to the absorbance changes at 390 , total time $20 \mathrm{~s}$ ). b) Plot at different temperatures of the dependence on 
[aniline] of the value of $k_{\mathrm{obs} 1}$ for the reaction observed. $c$ ) Plot of $\ln k_{\text {off } 1}$ for the same process at different pressures at $20^{\circ} \mathrm{C}$.

Table 2.- Kinetic, equilibrium and thermal activation parameters for the reaction between putative $\left[\mathrm{PtBr}_{5}\right]^{3-}$ and $\mathrm{C}_{6} \mathrm{H}_{5} \mathrm{NH}_{2}$ in $1.0 \mathrm{M}\left(\mathrm{Bu}_{4} \mathrm{P}\right) \mathrm{Br} \mathrm{CH}_{2} \mathrm{Br}_{2}$ solution.

\begin{tabular}{|c|c|c|c|c|c|}
\hline Step & ${ }^{293} k$ & ${ }^{293} K_{\text {eq }} / \mathrm{M}^{-1}$ & $\Delta H^{\ddagger} / \mathrm{kJ} \mathrm{mol}^{-1}$ & $\Delta S^{\ddagger} / \mathrm{J} \mathrm{K}^{-1} \mathrm{~mol}^{-1}$ & $\Delta V^{\ddagger} / \mathrm{cm}^{3} \mathrm{~mol}^{-1}$ \\
\hline$\underline{\text { on }}$ first & $0.16 \mathrm{M}^{-1} \mathrm{~s}^{-1}$ & \multirow{2}{*}{0.5} & $71 \pm 13$ & $-20 \pm 44$ & $\sim 0$ \\
\hline off first & $0.31 \mathrm{~s}^{-1}$ & & $91 \pm 5$ & $53 \pm 15$ & $19 \pm 2$ \\
\hline on second & $4.9 \times 10^{-3} \mathrm{M}^{-1} \mathrm{~s}^{-1}$ & \multirow{2}{*}{10} & $94 \pm 4$ & $30 \pm 14$ & \\
\hline off second & $4.3 \times 10^{-4} \mathrm{~s}^{-1}$ & & $52 \pm 10$ & $-134 \pm 35$ & \\
\hline$\underline{\text { on } \text { third }}$ & $5.4 \times 10^{-4} \mathrm{M}^{-1} \mathrm{~s}^{-1}$ & \multirow{2}{*}{15} & $94 \pm 16$ & $13 \pm 52$ & \\
\hline off third & $3.9 \times 10^{-5} \mathrm{~s}^{-1}$ & & $105 \pm 19$ & $29 \pm 65$ & \\
\hline
\end{tabular}

As seen in Table 2 all the processes measured show a definite equilibrium nature that must be very little displaced at the high bromide concentrations existing at the catalytic conditions of the target hydroamination process. All of them are, consequently, related to sequential bromide by aniline substitution. Some experiments were also carried out in order to establish the importance of bromide concentration for the first relevant process, $k_{\mathrm{obs} 1}$. As seen in Figure $4 \mathrm{a}$ an important increase of the reaction rate occurs on decreasing the amount of bromide ions in solution, which is indicative the need of a bromido dissociation for the formation of the final complex with the amine ligand in the $\mathrm{Pt}^{\mathrm{II}}$ coordination sphere. Given the high complexity of the sequential reactivity observed, no further studies were conducted at other $[(\mathrm{Bu} 4 \mathrm{P}) \mathrm{Br}]:\left[\mathrm{C}_{6} \mathrm{H}_{5} \mathrm{NH}_{2}\right]$ ratios. The same type of trend has also been observed in other systems, ${ }^{61-63}$ where an equilibrium leading to a lower coordination number species is responsible of the final substitution reaction observed. Summarizing, the process agrees with the set of reactions indicated in Equation 2 and 3 which produces the rate law indicated in Equation 4, once the steady state approximation has been applied to the $\left[\mathrm{PtBr}_{4}\left(\mathrm{PhNH}_{2}\right)\right]^{2-}$ intermediate species. ${ }^{48}$ 


$$
\begin{gathered}
{\left[\mathrm{PtBr}_{5}\right]^{3-}+\mathrm{PhNH}_{2} \underset{k_{-1}}{\stackrel{k_{1}}{\rightleftarrows}}\left[\mathrm{PtBr}_{4}\left(\mathrm{PhNH}_{2}\right)\right]^{2-}+\mathrm{Br}^{-}} \\
{\left[\mathrm{PtBr}_{4}\left(\mathrm{PhNH}_{2}\right)\right]^{2-} \underset{k_{-2}}{\stackrel{k_{2}}{\rightleftarrows}}\left[\mathrm{PtBr}_{3}\left(\mathrm{PhNH}_{2}\right)\right]^{-}+\mathrm{Br}^{-}} \\
k_{\text {obs } 1}=\frac{k_{1} k_{2}\left[\mathrm{PhNH}_{2}\right]}{k_{-1}\left[\mathrm{Br}^{-}\right]+k_{2}}+\frac{k_{-1} k_{-2}\left[\mathrm{Br}^{-}\right]}{k_{-1}\left[\mathrm{Br}^{-}\right]+k_{2}}
\end{gathered}
$$

Equation 4 becomes $k_{\text {obs1 }}=k_{\text {on_1st }}\left[\mathrm{PhNH}_{2}\right]+k_{\text {off_1st }}$ with $k_{\text {on_1st }}=\left\{k_{1} k_{2} /\left(k_{-1}\left[\mathrm{Br}^{-}\right]+k_{2}\right)\right\}$ and $k_{\text {off_1st }}=$ $\left\{k_{-1} k_{-2}\left[\mathrm{Br}^{-}\right] /\left(k_{-1}\left[\mathrm{Br}^{-}\right]+k_{2}\right)\right\}$. While only for $k_{2} \gg k_{-1}\left[\mathrm{Br}^{-}\right]$the actual rate constant measured has any specific significance with respect to $k_{\mathrm{on} \_1 \mathrm{st}}\left(=k_{1}\right)$, the $k_{2}<<k_{-1}\left[\mathrm{Br}^{-}\right]$approximation is needed for $k_{\text {off_lst }}$ to reduce to a significant rate constant, $k_{-2}$. Nevertheless, the decrease of $k_{\text {obs } 1}$ with $\left[\mathrm{Br}^{-}\right]$observed in Figure 4a needs the $k_{-1}\left[\mathrm{Br}^{-}\right]$term to be relevant not allowing for the first approximation. Further, the fact that the plot in Figure 4 a does not reach an asymptotic $k_{-2}$ limit also indicates that the second approximation cannot be applied for the $\left[\mathrm{Br}^{-}\right]$used in the study. The alternative approach, involving an initial bromide decoordination followed by a simple aniline by bromide substitution, can be disregarded in view of the very fast processes (within stopped-flow mixing time) observed for the $\left[\mathrm{PtBr}_{4}\right]^{2-}$ plus $\mathrm{PhNH}_{2}$ reaction. This fact should produce an effective substitution reaction rate as that measured for the back reaction indicated in the previous section, which is orders of magnitude slower that the observed. As a consequence, the values of the apparent thermal activation parameters derived from the measurements have to be taken very carefully and cannot be considered as a reliable tool for the assignation of the intimate mechanism operating. The apparent values for the on process indicate either an overall concerted mechanism for the bromido by aniline substitution or a dissociation of an already elongated $\mathrm{Pt}-\mathrm{Br}$ bond (as indicated in the previous section). Clearly the square pyramid structure of the putative $\left[\mathrm{PtBr}_{5}\right]^{3-}$ species formed on dissolution of the $\left[\mathrm{PtBr}_{4}\right]^{2-}$ in concentrated $\left(\mathrm{Bu}_{4} \mathrm{P}\right) \mathrm{Br}$ solutions is responsible for this behaviour as found for other $\mathrm{Ni}^{\mathrm{II}}$ complexes. ${ }^{56}$ For the reverse reaction, off, an overall dissociative exit of the aniline ligand seems to be operating, which agrees with the second possibility indicated. The complex nature of the rate constants determined (Equation 4) makes any further discussion useless. That is, according to Equations 2 and 3, $k_{1}$ seems to be dominant for the on process while $k_{-1}$ for the off reactions, in agreement with the microreversibility principle. Interestingly the values of 
$\Delta V^{\ddagger}$ determined for this faster process $\left(k_{\text {on_1st }}, k_{\text {off_1st }}\right)$ are very much in line with those measured for $\Delta S^{\neq}$which normally indicates the non-actuation of determinant hydrogen bonding in the transition state of the process. ${ }^{61,64,65}$

a)



b)

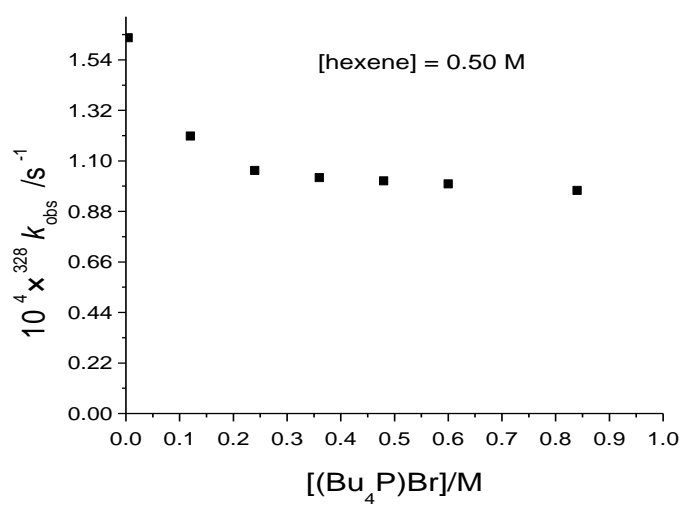

Figure 4.- $a)$ Plot of the values of $k_{\mathrm{obs} 1}$ versus $[(\mathrm{Bu} 4 \mathrm{P}) \mathrm{Br}]$ for the reaction of a solution of $2 \times 10^{-4} \mathrm{M}$ of putative $\left[\mathrm{PtBr}_{5}\right]^{3-}$ and $\left.0.11 \mathrm{M}^{-} \mathrm{C}_{6} \mathrm{H}_{5} \mathrm{NH}_{2}\right]\left(20^{\circ} \mathrm{C} . \boldsymbol{b}\right)$ Plot of the values of $k_{\mathrm{obs}}$ versus $\left[\left(\mathrm{Bu} \mathrm{B}_{4} \mathrm{P}\right) \mathrm{Br}\right]$ for the reaction of a solution of $2 \times 10^{-4} \mathrm{M}$ of putative $\left[\mathrm{PtBr}_{5}\right]^{3-}$ and $0.50 \mathrm{M}$ [hexene] $\left(45^{\circ} \mathrm{C}\right)$.

Evidently, the sequential second and third processes observed must have a different character if they are deriving from square-planar $\left[\mathrm{PtBr}_{3}\left(\mathrm{PhNH}_{2}\right)\right]^{-}$and $\left[\mathrm{PtBr}_{2}\left(\mathrm{PhNH}_{2}\right)_{2}\right]$ complexes.

Given the high complexity involved, the nature of the second and third processes observed was not further explored. Nevertheless, the formation of $c i s-\left[\mathrm{PtBr}_{2}\left(\mathrm{PhNH}_{2}\right)_{2}\right]$, as the more readily formed bis-aniline compound ${ }^{28,30}$ in a second step from $\left[\mathrm{PtBr}_{3}\left(\mathrm{PhNH}_{2}\right)\right]^{-}$or $\left[\mathrm{PtBr}_{4}\left(\mathrm{PhNH}_{2}\right)\right]^{2-}$, can be easily understood according to the set of reactions in Equation 2-3. Its transformation to the more stable trans- isomer, as the process that originates the third observed step, seems a reasonable speculation. The $\left[\mathrm{PhNH}_{2}\right]$-dependence of $k_{\text {obs } 3}$ agrees with this assumption taking into account the intermolecular character normally actuating for this type of isomerization processes (Figures S1 and S2, Supporting information). ${ }^{66}$

Reactivity of $\left[\mathrm{PtBr}_{4}\right]^{2-}$ with hexene in $\left(\mathrm{Bu}_{4} \mathrm{P}\right) \mathrm{Br}$ media The reactivity observed for $\left(\mathrm{Bu}_{4} \mathrm{P}\right)_{2}\left[\mathrm{PtBr}_{4}\right]$ with $\mathrm{PhNH}_{2}$ in a $\left(\mathrm{Bu}_{4} \mathrm{P}\right) \mathrm{Br} / \mathrm{CH}_{2} \mathrm{Br}_{2}$ medium, indicated in the previous section, as well as the reported partial ethylene dissociation from $\left[\mathrm{PtBr}_{3}\left(\mathrm{C}_{2} \mathrm{H}_{4}\right)\right]^{-}$in a $(\mathrm{Bu} 4 \mathrm{P}) \mathrm{Br} / \mathrm{CH}_{2} \mathrm{Cl}_{2}$ 
medium,${ }^{30}$ prompted us to parallel the above described study with a

$\left(\mathrm{Bu}_{4} \mathrm{P}\right)_{2}\left[\mathrm{PtBr}_{4}\right] /\left(\mathrm{Bu}_{4} \mathrm{P}\right) \mathrm{Br} / \mathrm{alkene}$ system in $\mathrm{CH}_{2} \mathrm{Br}_{2}$. The chosen alkene was 1-hexene (hexene from here on) given its relatively high boiling point that enables its easy and safe manipulation, as well as the reliability of the desired concentration levels during prolonged periods. This study is relevant given the preferential stability observed for $\left[\mathrm{PtBr}_{3}\left(\mathrm{C}_{2} \mathrm{H}_{4}\right)\right]^{-}$, with respect to $\left[\mathrm{PtBr}_{3}\left(\mathrm{PhNH}_{2}\right)\right]^{-}$, when cis- or trans- $\left[\mathrm{PtBr}_{2}\left(\mathrm{C}_{2} \mathrm{H}_{4}\right)\left(\mathrm{PhNH}_{2}\right)\right]$ complexes are dissolved in $\left(\mathrm{Bu}_{4} \mathrm{P}\right) \mathrm{Br} / \mathrm{CH}_{2} \mathrm{Cl}_{2}$ solutions. The improved catalyzed hydroamination reaction of 1-hexene with aniline in a $\left(\mathrm{Bu}_{4} \mathrm{P}\right) \mathrm{Br}$-rich environment has also been reported within the $0.10-0.23 \mathrm{M}$ range for $\left[\left(\mathrm{Bu}_{4} \mathrm{P}\right) \mathrm{Br}\right] /[$ hexene $],{ }^{14}$ which is included in the 0.11-0.53 margin used in this study (Table S1). In order to establish whether $\mathrm{CH}_{2} \mathrm{Br}_{2}$ solutions of the starting $\left[\mathrm{PrBr}_{4}\right]^{2-}$ complex react with hexene, preliminary UV-Vis monitoring of solutions of $\left(\mathrm{Bu}_{4} \mathrm{P}\right)_{2}\left[\mathrm{PtBr}_{4}\right]$ in dibromomethane with varying amounts of hexene was conducted in the absence of added $\left(\mathrm{Bu}_{4} \mathrm{P}\right) \mathrm{Br}$, in order to suppress the formation of the putative $\left[\mathrm{PtBr}_{5}\right]^{3-}$. Under these conditions reactivity is effectively observed (Figure S3) leading to the probable formation of $\left[\mathrm{PtBr}_{3}(\text { hexene) }]^{-}\right.$, by analogy with complex $\left[\mathrm{PtBr}_{3}\left(\mathrm{C}_{2} \mathrm{H}_{4}\right)\right]^{-}$that has been previously prepared under similar conditions. ${ }^{30}$ Nevertheless, when the experiments were conducted on the same $\left(\mathrm{Bu}_{4} \mathrm{P}\right)\left[\mathrm{PtBr}_{4}\right] /\left(\mathrm{Bu}_{4} \mathrm{P}\right) \mathrm{Br}$ equilibrated mixtures used for the aniline reactivity studies indicated in the previous section, the process occurred on a much longer time-scale. Solutions of $\left(\mathrm{Bu}_{4} \mathrm{P}\right)_{2}\left[\mathrm{PtBr}_{4}\right]$ in the (2$5) \times 10^{-4} \mathrm{M}$ range in $\left(\mathrm{Bu}_{4} \mathrm{P}\right) \mathrm{Br} / \mathrm{CH}_{2} \mathrm{Br}_{2}\left(0.02-2.0 \mathrm{M}\left(\mathrm{Bu}_{4} \mathrm{P}\right) \mathrm{Br}\right.$ concentration margin) treated with varying amounts (0.1-0.9 $\mathrm{M}$ ) of hexene only showed a significant reaction when very long periods or high temperatures were used. As a consequence, the $\left(\mathrm{Bu}_{4} \mathrm{P}\right) \mathrm{Br}$ concentration was set to $0.08 \mathrm{M}$ in order to facilitate the monitoring. Figure 5 collects some relevant information about these experiments. From the time resolved recorded spectra it is clear that under these conditions a neat process occurs. The observed rate constants show an important degree of equilibrium, as indicated by the intercepts in the plot of $k_{\mathrm{obs}}$ versus [hexene] (Figure 5b).The temperature and pressure dependence of the slopes and intercepts derived from these plots produce the thermal and pressure activation parameters collected in Table 3 using the standard Eyring and $\ln k_{\text {on }}$ and $\ln k_{\text {off }}$ versus $P$ plots. The effect of the $\left(\mathrm{Bu}_{4} \mathrm{P}\right) \mathrm{Br}$ concentration on these reaction rates was also studied in view of the results found for the $\left(\mathrm{Bu}_{4} \mathrm{P}\right)_{2}\left[\mathrm{PtBr}_{4}\right] /\left(\mathrm{Bu}_{4} \mathrm{P}\right) \mathrm{Br} /$ aniline system. Figure $4 \mathrm{~b}$ shows the observed changes for the $k_{\mathrm{obs}}$ value at $55{ }^{\circ} \mathrm{C}$ when $\mathrm{CH}_{2} \mathrm{Br}_{2} 2.5 \times 10^{-4} \mathrm{M}$ solutions of putative $\left[\mathrm{PtBr}_{5}\right]^{3-}$ were reacted with hexene $(0.5 \mathrm{M})$ in the $0.05-2.0 \mathrm{M}\left(\mathrm{Bu}_{4} \mathrm{P}\right) \mathrm{Br}$ concentration. 
Table 3.- Kinetic, equilibrium and thermal activation parameters for the reaction between putative $\left[\mathrm{PtBr}_{5}\right]^{3-}$ and hexene in $0.1 \mathrm{M}\left(\mathrm{Bu}_{4} \mathrm{P}\right) \mathrm{Br} \mathrm{CH}_{2} \mathrm{Br}_{2}$ solution.

\begin{tabular}{c|c|c|c|c|c} 
Step & ${ }^{328} k$ & ${ }^{\text {average }} K_{\mathrm{eq}} / \mathrm{M}^{-1}$ & $\Delta H^{\ddagger} / \mathrm{kJ} \mathrm{mol}^{-1}$ & $\Delta S^{\ddagger} / \mathrm{J} \mathrm{K}^{-1} \mathrm{~mol}^{-1}$ & $\Delta V^{\ddagger} / \mathrm{cm}^{3} \mathrm{~mol}^{-1}$ \\
\hline$\underline{\text { on }}$ & $2.4 \times 10^{-4} \mathrm{M}^{-1} \mathrm{~s}^{-1}$ & \multirow{2}{*}{13} & $70 \pm 2$ & $-105 \pm 6$ & $-11 \pm 2$ \\
\cline { 1 - 4 } off & $1.6 \times 10^{-5} \mathrm{~s}^{-1}$ & & $65 \pm 5$ & $-145 \pm 15$ & $-28 \pm 3$ \\
\hline \hline
\end{tabular}

a)

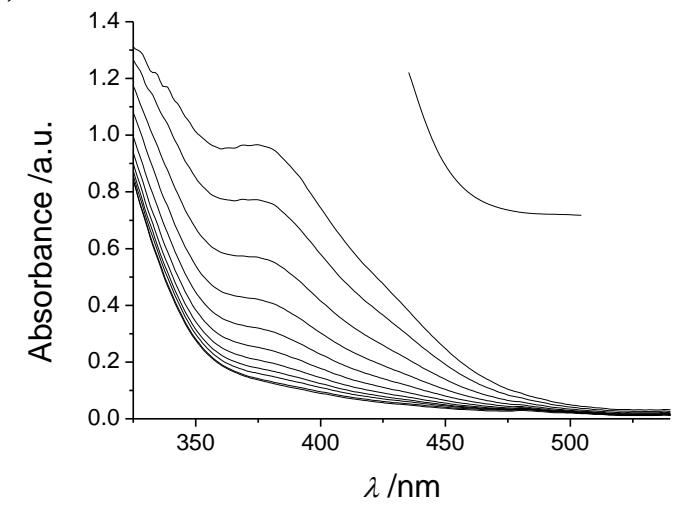

b)

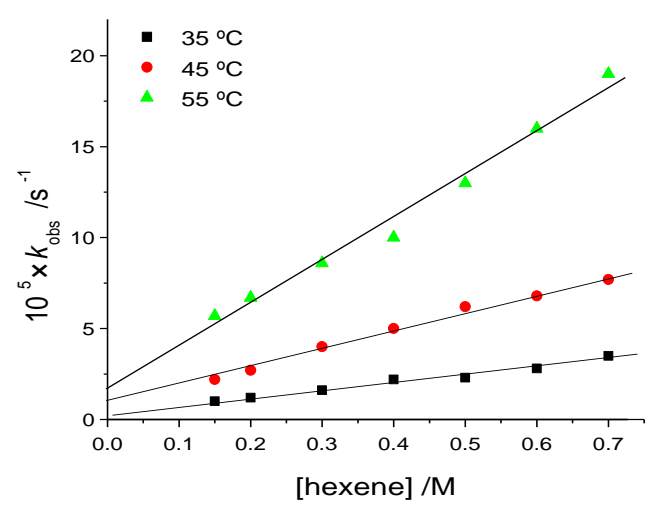

Figure 5.- a) Time resolved UV-Vis spectra of the evolution of a $\mathrm{CH}_{2} \mathrm{Br}_{2}$ solution of putative $\left[\mathrm{PtBr}_{5}\right]^{3-}$ $\left(2.5 \times 10^{-4} \mathrm{M}\right),\left(\mathrm{Bu}_{4} \mathrm{P}\right) \mathrm{Br}(0.13 \mathrm{M})$ and hexene $(0.08 \mathrm{M})$ at $55^{\circ} \mathrm{C}$ and $900 \mathrm{~atm}$. (inset corresponds to the absorbance changes at $375 \mathrm{~nm}$, total time $15000 \mathrm{~s}$ ). b) Plot of the dependence on [hexene] of $k_{\text {obs }}$ at different temperatures.

$$
\begin{gathered}
{\left[\mathrm{PtBr}_{5}\right]^{3-} \underset{k_{+}}{\stackrel{k_{-}}{\rightleftarrows}}\left[\mathrm{PtBr}_{4}\right]^{2-}+\mathrm{Br}^{-}} \\
{\left[\mathrm{PtBr}_{4}\right]^{2-}+\text { hexene } \stackrel{k_{3}}{\rightleftarrows}\left[\mathrm{PtBr}_{3}(\text { hexene })\right]^{-}+\mathrm{Br}^{-}} \\
k_{\text {obs }}=\frac{k_{-} k_{3}[\text { hexene }]}{k_{+}\left[\mathrm{Br}^{-}\right]+k_{3}[\text { hexene }]}+\frac{k_{+} k_{-3}\left[\mathrm{Br}^{-}\right]^{2}}{k_{+}\left[\mathrm{Br}^{-}\right]+k_{3}[\text { hexene }]}
\end{gathered}
$$

In this process the values obtained for $k_{\mathrm{obs}}$ are close to those observed for the $\left[\mathrm{PtBr}_{4}\right]^{2-} / \mathrm{Br}^{-}$ equilibration process indicated before, and the alternative mechanism shown in Equations 5-7, 
involving the preliminary dissociation of a bromido ligand from the putative $\left[\mathrm{PtBr}_{5}\right]^{3-}$, could be operating. If the $k_{+}\left[\mathrm{Br}^{-}\right]>k_{3}$ [hexene] approximation applies, the rate law in Equation 7 fits the trend of the data in Figure $4 \mathrm{~b}$ and $5 \mathrm{~b}$ with $k_{\text {on }}=k-k_{3}[$ hexene $] / k_{+}\left[\mathrm{Br}^{-}\right]$and $k_{\text {off }}=k_{-3}\left[\mathrm{Br}^{-}\right]$. Nevertheless, at $36^{\circ} \mathrm{C}$ the values of $k_{+3}$ and $k_{-3}$ were determined as $2.0 \times 10^{-3} \mathrm{M}^{-1} \mathrm{~s}^{-1}$ and $2.1 \times 10^{-3} \mathrm{~s}^{-1}$ respectively (Figure S3b), which should produce a value for $k_{\text {off }} \approx(1-2) \times 10^{-4} \mathrm{~s}^{-1}$ under the conditions of the study at $35^{\circ} \mathrm{C}$. The fact that the experimental value determined is two orders of magnitude smaller $\left(3.1 \times 10^{-6} \mathrm{~s}^{-1}\right.$, Figure $\left.5 \mathrm{~b}\right)$ indicates that the alternative mechanism does not effectively fit the data obtained. That is, the mechanism and rate law shown in Equations 2-4 with hexene as entering ligand instead of aniline $\left(k_{1^{\prime}}, k_{-1^{\prime}}, k_{2^{\prime}}\right.$ and $\left.k_{-2^{\prime}}\right)$ applies. In this respect it is important to note that at high $\left[\mathrm{Br}^{-}\right]$values there seems to be a limiting value for $k_{\mathrm{obs}}$ at $55^{\circ} \mathrm{C}$ of $c a .1 \times 10^{-4} \mathrm{~s}^{-1}$ (Figure $4 \mathrm{~b}$ ), the same within error than $k$-for the $\left[\mathrm{PtBr}_{4}\right]^{2-} / \mathrm{Br}^{-}$system. Even though Equation 7 can explain this fact via a compensation of the $k_{+}\left[\mathrm{Br}^{-}\right]$and $k_{+} k_{-3}\left[\mathrm{Br}^{-}\right]^{2}$ terms, we are tempted to believe that at high $\mathrm{Br}^{-}$concentrations the coordination of hexene to the system is totally suppressed and that only the re-equilibration reaction to the new lower $\left[\mathrm{Br}^{-}\right]$(from 1.0 to $0.08 \mathrm{M}$, see before) is being observed.

Similarly to the aniline substitution process, the complex nature $\left(k_{1^{\prime}}, k_{-1^{\prime}}, k_{2^{\prime}}\right.$ and $\left.k_{-2^{\prime}}\right)$ of the values obtained for $k_{\text {on }}$ and $k_{\text {off }}$ do not allow for a reliable discussion about the intimate reaction mechanism, given the fact that the activation parameters are only apparent values. These values, collected in Table 3, are fairly negative for both $\Delta S^{\dagger}$ and $\Delta V^{\ddagger}$, which can be associated with an associative character of the overall substitution process. This is accompanied with relatively small values for the activation enthalpies. The values are in clear contrast with the corresponding data in Table 2 for the reaction with aniline where a concerted or dissociative character can be interpreted from the activation parameters. It is evident that the mechanism operating for the alkene coordination to the platinum centre is not the same as that occurring for the aniline. While for the aniline entry the $k_{1} / k_{-1}$ reaction path fits the activation parameters determined, in this case the values for $\Delta H^{\ddagger}, \Delta S^{\ddagger}$ and $\Delta V^{\ddagger}$ are all indicative of a process with a very important associative character much more in line with what would be expected for the $k_{2} / k_{-2}$ reaction path.

Reactivity of $\left[\mathrm{PtBr}_{4}\right]^{2-}$ in $\left(\mathrm{Bu} \mathrm{u}_{4} \mathrm{P}\right) \mathrm{Br} /$ aniline/hexene media In order to determine the reactivity of the platinum species simultaneously with both relevant ligands, a set of experiments was also conducted, on preformed $\left[\mathrm{PtBr}_{5}\right]^{3-}$, with hexene and aniline at varying concentrations, 
temperatures and times. At short reaction times a fast reaction occurs which follows the same kinetic pattern than that observed solely with $\mathrm{PhNH}_{2}$. When the processes were monitored by $\mathrm{UV}-\mathrm{V}$ is for longer times, some further changes were observed that were fully equivalent to those obtained in blank experiments without hexene added to the reaction medium, thus indicating that a mere aniline side decomposition process was being observed. These results indicate that hexene has a lower coordinating ability than aniline for $\mathrm{Pt}^{\mathrm{II}}$ under this specific coordination environment (bromide-rich solution in a polar solvent), whereas it was previously concluded that ethylene binds to $\left[\mathrm{PtBr}_{4}\right]^{2-}$ more favourably than aniline in non-ionic medium. ${ }^{30}$ The simplest explanation consists on considering the equilibrium indicated in Equation 8 very displaced to the left for ethylene and to the right for hexene. Indeed, a recent computational study confirms that 1-hexene coordination provides lower stabilization relative to ethylene. ${ }^{29}$ Given the fact that steric hindrance of the alkene cannot be held responsible for the difference in such an open environment, the origin should be electronic. Hexene is a better $\sigma$-donor but a poorer $\pi$-acceptor than ethylene, thus a worse ligand if back-bonding is dominant for the stabilization of the Pt-alkene bound in the complex. Nevertheless, the reaction media for the two studies are by no means equivalent. The important excess of bromide ions in the reaction medium enables the actuation of the equilibrium reactions indicated by Equation 2 and $3\left(k_{1}\right.$, $\left.k_{-1}, k_{2}, k_{-2}\right)$ as well as the equivalent for hexene $\left(k_{1^{\prime}}, k_{-1^{\prime}}, k_{2}, k_{-2^{\prime}}\right)$ and thus generates a much more complex system.

$$
\left[\mathrm{PtBr}_{3}(\text { alkene })\right]^{-}+\mathrm{PhNH}_{2} \rightleftharpoons\left[\mathrm{PtBr}_{3}\left(\mathrm{PhNH}_{2}\right)\right]^{-}+\text {alkene }
$$

Summarising, the present study is fully relevant to shed light to the mechanism of olefin hydroamination in highly ionic medium in terms of the identification of the dormant species of the catalytic cycle. Although it has been established as $\left[\mathrm{PtBr}_{3}\left(\mathrm{C}_{2} \mathrm{H}_{4}\right)\right]^{-}$(for the hydroamination of ethylene in fully organic solvents), ${ }^{28,30}$ the results indicated that the kinetically preferred species is an aniline complex without coordinated olefin, such as $\left[\mathrm{PtBr}_{3}\left(\mathrm{PhNH}_{2}\right)\right]^{-}$or possibly $\left[\mathrm{PtBr}_{2}\left(\mathrm{PhNH}_{2}\right)_{2}\right]$, when dealing with the hydroamination of 1-hexene in $\left(\mathrm{Bu}_{4} \mathrm{P}\right) \mathrm{Br} / \mathrm{CH}_{2} \mathrm{Br}_{2}$ medium. Nevertheless, the considerations about the intimate hydroamination mechanism, occurring via much higher-energy transition states, according to the recent computational study, ${ }^{28}$ do not have to be altered so far given the fact that all ligand exchange reactions occur with relative low activation barriers. 


\section{EXPERIMENTAL}

\section{Instruments}

${ }^{195} \mathrm{Pt}$ NMR spectra were recorded on a Bruker 500 spectrometer in $\mathrm{CDCl}_{3}$ at room temperature at the Institut Català d'Investigació Química; chemical shifts are reported in ppm, referred to $\mathrm{H}_{2}\left[\mathrm{PtCl}_{6}\right] \cdot{ }^{31} \mathrm{P}$ and ${ }^{1} \mathrm{H}$ NMR spectra were recorded on a Varian Unity $300\left({ }^{31} \mathrm{P}, 121.42 \mathrm{MHz}\right)$ or on a Mercury $400\left({ }^{1} \mathrm{H}, 400 \mathrm{MHz}\right)$ instruments and referenced to $\mathrm{SiMe}_{4}\left({ }^{1} \mathrm{H}\right)$ or $\mathrm{H}_{3} \mathrm{PO}_{4}\left({ }^{31} \mathrm{P}\right)$ at the Unitat de RMN d'Alt Camp (Universitat de Barcelona).

The UV-Vis spectra and the kinetic monitoring of the reactions were recorded in a HewlettPackard 8453A, a Cary 50 or a J\&M TIDAS instrument, depending on the experiments. The pressurising system used for the experiments run at variable pressure has already been described. ${ }^{67,68}$ In all cases a pill-box cell has been chosen for the experiments. ${ }^{69}$

\section{Compounds}

$\left(\mathrm{Bu}_{4} \mathrm{P}\right)_{2}\left[\mathrm{PtBr}_{4}\right]$ was obtained via chlorido by bromido exchange on $\mathrm{K}_{2}\left[\mathrm{PtCl}_{4}\right]$ in aqueous solution, followed by treatment and extraction with a saturated solution of $\left(\mathrm{Bu}_{4} \mathrm{P}\right) \mathrm{Br}$ in $\mathrm{CH}_{2} \mathrm{Cl}_{2}$ as indicated in the literature. ${ }^{24}$ Repetitive washing with water of the organic layer and evaporation to dryness produced the desired compound. The use of commercially available $\mathrm{K}_{2}\left[\mathrm{PtBr}_{4}\right]$ was avoided after an important number of experiments carried out indicated that the purchased compound does not agree with the specifications indicated. ${ }^{195} \mathrm{Pt}$ NMR resonance of a commercial sample indicated the presence of only minor quantities of the tetrabromido species, while mixed bromido/chlorido compounds were dominant. $\left(\mathrm{Bu}_{4} \mathrm{P}\right) \mathrm{Br}, \mathrm{C}_{4} \mathrm{H}_{9} \mathrm{CH}=\mathrm{CH}_{2}$ and $\mathrm{CH}_{2} \mathrm{Br}_{2}$ were reagent grade chemicals and have been used without further treatment. $\mathrm{PhNH}_{2}$ was vacuum distilled and kept in the dark under nitrogen atmosphere before use.

\section{Kinetic measurements}

The progress of the different processes studied in dibromomethane solution was followed by $\mathrm{UV}-\mathrm{Vis}$ spectroscopy in the wavelength range where the solvent does not absorb. All the reactions at atmospheric pressure were monitored on instruments equipped with thermostated multicell transports. The general kinetic technique for this type of processes has been described elsewhere. ${ }^{40,42,70}$ For the kinetic runs at elevated pressure, a previously described pressurizing system connected to a J\&M TIDAS instrument was used. ${ }^{71}$ Observed rate constants were derived from absorbance versus time traces at the wavelength were a maximum increase and/or decrease of absorbance was observed by the use of the SPECFIT software. ${ }^{72}$ No dependence of 
the observed rate constants on the selected wavelength was detected; for some reactions a good retention of isosbestic points was observed.$^{73}$ The supporting information collects the obtained kinetic constants values for all the reactions studied, as a function of aniline, hexene and tetrabutylphosphonium bromide concentrations, pressure and temperature. The errors in all cases were within the 10-15\% margin. All post-run fitting were carried out with the commercial software available and using non-weighted least-square methods. Typical errors were $10-15 \%$ for slopes and intercepts and 15-18 \% for asymptotic limits.

\section{Supplementary Material Available}

Supplementary material is available via the Internet. This includes: values of $k_{\text {obs }}$ determined as a function of the compounds, concentration, temperature and pressure and some relevant figures.

Acknowledgements Financial support from the Ministerio de Educación y Ciencia and the Generalitat de Catalunya, grant numbers CTQ2009-14443-C02-02, CTQ2008-06670-C0201 and 2009SGR-1459 is acknowledged. We also thank the "Laboratoire European Associé" CTPMM (Chimie Trans-Pyrénéenne: de la Molécule aux Matériaux), co-funded by French CNRS and the Generalitat de Catalunya, for a travel grant to MRZ. 


\section{REFERENCES}

1.- $\quad$ Brunet, J. J.; Neibecker, D. Catalytic Heterofunctionalization; VCH: Weinheim, 2001; pp 91-141.

2.- $\quad$ Müller, T. E.; Hultzsch, K. C.; Yus, M.; Foubelo, F.; Tada, M. Chem.Rev. 2008, 108, 3795-3892.

3.- $\quad$ Ryu, J. S.; Li, G. Y.; Marks, T. J. J.Am.Chem.Soc 2003, 125, 12584-12605.

4.- $\quad$ Hong, S.; Marks, T. J. Acc.Chem.Res 2004, 37, 673-686.

5.- $\quad$ Yang, L.; Xu, LL. W.; Zhou, W.; Gao, Y. H.; Sun, W.; Xia, C. G. Syn.Lett. 2009, 1167-1171.

6.- $\quad$ Gadner, D. M. and Clark, R. T. Patent US 4,454,321 1984.

7.- $\quad$ Schaffrath, H.; Keim, W. J.Mol.Catal.A 2001, 168, 9-14.

8.- Yi, C. S.; Yun, Y. Org.Lett 2005, 7, 2181-2183.

9.- Coulson, D. R. Tetrahedron Lett. 1971, 429-430.

10.- Coulson, D. R. Patent US3, 758, 5861973.

11.- Diamond, S. E.; Mares, F.; Szalkiewicz, A. Fundam.Res.Homog.Catal 1979, 3, 345-358.

12.- Diamond, S. E. and Mares, F. Patent US 4, 215, 2181980.

13.- Brunet, J. J.; Cadena, M.; Chu, N. C.; Diallo, O.; Jacob, K.; Mothes, E. Organometallics 2004, 23, 1264-1268.

14.- Brunet, J. J.; Chu, N. C.; Diallo, O. Organometallics 2005, 24, 3104-3110.

15.- Rodríguez-Zubiri, M.; Anguille, S.; Brunet, J. J. J.Mol.Catal.A 2007, 271, 145-150.

16.- Dub, P. A.; Rodríguez-Zubiri, M.; Baudequin, C.; Poli, R. Green Chem. 2010, 1392-1396.

17.- Wang, X.; Widenhofer, R. A. Organometallics 2004, 23, 1649-1651.

18.- Karstedt, D.; Bell, A. T.; Tilley, T. D. J.Am.Chem.Soc 2005, 127, 12640-12646.

19.- McBee, J. L.; Bell, A. T.; Tilley, T. D. J.Am.Chem.Soc. 2008, 130, 16562-16571.

20.- Giner, X.; Najera, C. Syn.Lett. 2009, 3211-3213.

21.- Liu, X. Y.; Li, C. H.; Che, C. M. J.Am.Chem.Soc 2006, 128, 1798-1799.

22.- Giner, X.; Najera, C. Org.Lett 2008, 10, 2922.

23.- Zang, Z. B.; Lee, S. D.; Widenhofer, R. A. J.Am.Chem.Soc 2009, 131, 5372-5373.

24.- Brunet, J. J.; Chu, N. C.; Rodriguez-Zubiri, M. Eur.J.Inorg.Chem. 2007, 4711-4722.

25.- Tsipis, C. A.; Kefalidis, C. E. J.Organomet.Chem. 2007, 692, 5245-5255.

26.- Dub, P. A.; Filippov, O. A.; Belkova, N. V.; Rodríguez-Zubiri, M.; Poli, R. J.Phys.Chem.A 2009, $113,6348-6355$.

27.- Dub, P. A.; Poli, R. J.Mol.Catal.A 2010, 324, 89-96.

28.- Dub, P. A.; Poli, R. J.Am.Chem.Soc. 2010, 132, 13799-13812.

29.- Dub, P. A.; Poli, R. Organometallics 2011, Submitted.

30.- Dub, P. A.; Rodriguez-Zubiri, M.; Daran, J. C.; Brunet, J. J.; Poli, R. Organometallics 2009, 28, 4764-4777.

31.- Garcia-Amorós, J.; Martínez, M.; Finkelman, H.; Velasco, D. J.Phys.Chem.A 2010, 114, 12871293.

32.- Bell, C. A.; Bernhardt, P. V.; Gahan, L. R.; Martínez, M.; Monteiro, M. J.; Rodríguez, C.; Sharrad, C. A. Chem.Eur.J. 2010, 16, 3166-3175.

33.- Aullón, G.; Chat, R.; Favier, I.; Font-Bardía, M.; Gómez, M.; Granell, J.; Martínez, M.; Solans, X. Dalton Trans. 2009, 8292-8300.

34.- Basallote, M. G.; Bozoglián, F.; Fernandez-Trujillo, M. J.; Martínez, M. New J.Chem. 2007, 32, 264-272.

35.- Pérez-Tejada, P.; López-Pérez, G.; Prado-Gotor, R.; Sánchez, F.; González-Arjona, D.; LópezLópez, M.; Bozoglián, F.; González, G.; Martínez, M. Inorg.Chim.Acta 2006, 359, 149-158.

36.- Aullón, G.; Bernhardt, P. V.; Bozoglián, F.; Font-Bardía, M.; Macpherson, B. P.; Martínez, M.; Rodríguez, C.; Solans, X. Inorg.Chem. 2006, 45, 8551-8562.

37.- Bernhardt, P. V.; Bozoglián, F.; Macpherson, B. P.; Martínez, M.; Merbach, A. E.; González, G.; Sienra, B. Inorg.Chem. 2004, 43, 7187-7195.

38.- Crespo, M.; Font-Bardía, M.; Granell, J.; Martínez, M.; Solans, X. Dalton Trans. 2003, 37633769.

39.- Gómez, M.; Granell, J.; Martínez, M. Inorg.Chem.Commun. 2002, 5, 67-70. 
40.- Calvet, T.; Crespo, M.; Font-Bardía, M.; Gómez, K.; González, G.; Martínez, M. Organometallics 2009, 28, 5096-5106.

41.- Esteban, J.; Hirva, P.; Lahuerta, P.; Martínez, M. Inorg.Chem. 2006, 45, 8776-8784.

42.- Estevan, F.; González, G.; Lahuerta, P.; Martínez, M.; Peris, E.; van Eldik, R. J.Chem.Soc., Dalton Trans. 1996, 1045-1050.

43.- Bagnoli, F.; Dell'Amico, D. B.; Calderazzo, F.; Englert, U.; Marchetti, F.; Merigo, A.; Ramello, S. J.Organomet.Chem. 2001, 622, 180-189.

44.- Kramer, J.; Koch, K. R. Inorg.Chem. 2006, 45, 7843-7855.

45.- Still, B. M.; Kumar, P. G. A.; Aldrich-Wright, J. A.; Price, W. S. Chem.Soc.Rev. 2007, 36, 665686.

46.- Albrecht, M.; Lutz, M.; Spek, A. L.; van Koten, G. Nature 2000, 406, 970-974.

47.- Albrecht, M.; Rodríguez, G.; Schoenmaker, J.; van Koten, G. Org.Lett. 2000, 2, 3461-3464.

48.- Espenson, J. H. Chemical Kinetics and Reaction Mechanisms; McGraw-Hill: 1981.

49.- Tobe, M. L.; Burgess, J. Inorganic Reaction Mechanisms; Longman: 1999.

50.- Reichardt, C. Chem.Rev. 1994, 94, 2319-2358.

51.- Hofer, T. S.; Randolf, B. R.; Rode, B. M.; Persson, I. Dalton Trans. 2009, 1512-1515.

52.- Jalilehvand, F.; Laffin, L. J. Inorg.Chem. 2008, 47, 3248-3254.

53.- Purans, J.; Fourest, B.; Cannes, C.; Sladkov, V.; David, F.; Venault, L.; Lecomte, M. J.Phys.Chem.B 2005, 109, 11074-11082.

54.- Caminiti, R.; Carbone, M.; Sadun, C. J.Mol.Liq. 1998, 75, 149-158.

55.- Griffith, W. P.; Lane, J. R. J.Chem.Soc., Dalton Trans. 1972 , 158-159.

56.- Helm, L.; Meier, P.; Merbach, A. E.; Tregloan, P. A. Inorg.Chim.Acta 1983, 73, 1-9.

57.- Wilkins, R. G. Kinetics and Mechanisms of Reactions of Transition Metal Complexes; VCH: Weinheim, 1991.

58.- Roiban, G. D.; Serrano, E.; Soler, T.; Aullón, G.; Grosu, I.; Martínez, M.; Urriolabeitia, E. P. Unpublished results 2011.

59.- Illner, P.; Begel, S.; Kern, S.; Puchta, R.; van Eldik, R. Inorg.Chem. 2009, 48, 588-597.

60.- Partial optimization data indicate that, even though the formation of a $\left[\mathrm{PtBr}_{5}\right]^{3-}$ species in solution is an inherently unfavourable process, its degree of stabilization by simple ion-paring considerations is enormous, specially in non-polar media.

61.- Bernhardt, P. V.; Gallego, C.; Martínez, M.; Parella, T. Inorg.Chem. 2002, 41, 1747-1754.

62.- Esteban, J.; Font-Bardia, M.; Gallego, C.; González, G.; Martínez, M.; Solans, X. Inorg.Chim.Acta 2003, 351, 269-277.

63.- McAlister, D. R.; Bercaw, J. E.; Bergman, R. G. J.Am.Chem.Soc. 1998, 99, 1666-1668.

64.- Bernhardt, P. V.; Bozoglián, F.; Macpherson, B. P.; Martínez, M.; González, G.; Sienra, B. Eur.J.Inorg.Chem. 2003, 2512-2518.

65.- Bernhardt, P. V.; Martínez, M.; Rodríguez, C. Eur.J.Inorg.Chem. 2010, 5621-569.

66.- Cross, R. J. Chem.Soc.Rev. 1985, 197-223.

67.- Martínez, M.; Pitarque, M. A.; van Eldik, R. J.Chem.Soc., Dalton Trans. 1994, 3159-3163.

68.- Martínez, M.; Pitarque, M. A.; van Eldik, R. J.Chem.Soc., Dalton Trans. 1996, 2665-2671.

69.- van Eldik, R. Inorganic High Pressure Chemistry; Elsevier: 1986; Chapter 1, pp 1-68.

70.- Favier, I.; Gómez, M.; Granell, J.; Martínez, M.; Font-Bardía, M.; Solans, X. Dalton Trans. 2005, 123-132.

71.- Basallote, M. G.; Duran, J.; Fernandez-Trujillo, M. J.; González, G.; Máñez, M. A.; Martínez, M. Inorg. Chem. 1998, 37, 1623-1628.

72.- Binstead, R. A.; Zuberbuhler, A. D.; Jung, B. SPECFIT32. [3.0.34]. 2005. Spectrum Software Associates.

73.- Perkampus, H. H. Uv-Vis Spectroscopy and its Applications; Springer: 1992. 


\section{TOC synopsis}

The kinetico-mechanistic study of the reactivity of $\left[\mathrm{PtBr}_{4}\right]^{2-}$ in highly ionic $\left(\mathrm{Bu}_{4} \mathrm{P}\right) \mathrm{Br} / \mathrm{CH}_{2} \mathrm{Br}_{2}$ medium, very similar to that used in hydroamination reactions with one of the most active systems currently reported, indicates the formation of a pentacoordinate $\left[\mathrm{PtBr}_{5}\right]^{3-}$ unit as a stable species.



